\title{
EFFECTIVENESS OF ONLINE TEACHING DURING COVID-19 PANDEMIC FOR WEST MIDLANDS UROLOGY TRAINEES
}

\author{
Anton Wong
}

Department of Urology, Hereford County Hospital, Wye Valley NHS Trust, United Kingdom

${ }^{*}$ Corresponding author: Anton Wong

Email: antonwong@doctors.org.uk

\begin{abstract}
Background and Objective

Urology trainees in the West Midlands are provided with protected compulsory teaching sessions by the deanery. These teaching sessions are usually held in a regional centre, on a face-to-face basis. However, the coronavirus (COVID-19) pandemic has had a profound impact not only on individuals, the healthcare system, but has affected medical education for trainees. All regional teaching sessions have been moved online for the safety of individuals and to comply with social distancing guidelines. The aim of this study is to evaluate the effectiveness of online teaching during the pandemic.
\end{abstract}

\section{Material and Methods}

An online survey was sent out to all urology trainees in the West Midlands. The questionnaire, comprised of a mixture of open, closed and Likert-10-point scale questions was used to compare online teaching against face-to-face teaching. An independent t-test was carried out as the data was presumed to follow a normal distribution. Statistical significance was set at $\mathrm{p}<0.05$.

\section{Results}

$70 \%$ of trainees responded and participated in the survey. Attendance rates were higher when teaching was online compared to face-to-face sessions. $100 \%$ of trainees were able to attend at least $80 \%$ of online teaching sessions whilst $89 \%$ were able to attend face-to-face sessions. However, the quality of teaching were not statistically significant between face-to-face and online teaching sessions (mean $=7.95$ and 8.11 respectively, $\mathrm{p}=0.316$ ). The study found that trainees benefited from the accessibility of online teaching sessions but lost out on social networking and interactivity of face-to-face sessions. Most participants recommended a hybrid or blended learning approach once the pandemic is over.

\section{Conclusion}

The impact of COVID-19 has almost forced all undergraduate and postgraduate education to have a form of virtual presence. All teaching sessions will remain online for the foreseeable future. Our study found no difference between the qualities of teaching for both approaches. However, benefits and drawbacks of online teaching have been identified. Hence, we recommend a mixed learning approach of face-to-face and online teaching for the future.

Keywords: COVID-19, urology training, online teaching, face-to-face teaching, blended approach 


\section{INTRODUCTION}

Specialist urology training in the United Kingdom (UK) is currently 5 years in duration, from ST3 to ST7. During this period of training, urology trainees received allocated protected teaching days on top of their usual hospital training. In the West Midlands, urology trainees are provided with a complete and varied regional teaching programme, which comprises 15 full days of teaching sessions a year. ${ }^{1}$ Trainees are encouraged to attend all teaching days, but an attendance of at least $70 \%$ a year is compulsory.

Regional teaching sessions were traditionally taught in person, with trainees from the across the deanery gathering together. The impact of the coronavirus (COVID-19) pandemic is profound not only on physical health, the healthcare system but also on medical education and routine teaching sessions across the globe. ${ }^{2,3}$ Since the start of the pandemic, the deanery has made the decision to move all regional teaching sessions online, providing a virtual presence for the trainees.

\section{AIM}

The aim of this study is to evaluate the effectiveness of the online regional teaching sessions for West Midlands urology trainees during the COVID-19 pandemic. As this is still a relatively new concept, we do not yet know the long-lasting impact it would have on education and urology training. However, as the online teaching programme has been implemented for over 6 months, we would be able to explore the perceptions of postgraduate urology trainees in the deanery.

\section{METHODS}

An invitation to participate along with an online survey was sent out to all urology trainees in the West Midlands ( $\mathrm{n}=27$ ). The questionnaire, comprised of a mixture of open, closed and Likert-10-point scale questions was used to compare online teaching against face-to-face teaching. The data was then analysed. An independent t-test was performed as the data was presumed to follow a normal distribution. Statistical significance was set at $\mathrm{p}<0.05$.

\section{RESULTS}

A total of 19 participants (70\%) responded to the survey. The results are as below in Figures 2-6.

\section{DISCUSSION}

As a result of the COVID-19 pandemic, most medical schools and postgraduate specialities have swiftly adapted to distanced learning via online teaching. ${ }^{3-5}$ This is evident within the UK and across the globe. ${ }^{6-8}$ However, e-learning has always played a role in medical education. ${ }^{9}$ This study assesses the perception of online teaching sessions among urology trainees, with the aim of evaluating the effectiveness of online teaching.

\section{Would Attendance Rate Improve with Distanced Learning via Online Teaching?}

Although only $70 \%$ of the regional teaching is compulsory, all trainees are encouraged to attend all teaching sessions if possible. We compared the attendance of trainees between face-to-face teaching and online teaching sessions. As all trainees would need at least $70 \%$ attendance rate, our questionnaire determined if the trainees were able to attend at least $80 \%$ of the compulsory sessions. Overall, $89 \%(n=17)$ of trainees were able to attend at least $80 \%$ of the scheduled face-to-face teaching sessions prior to the pandemic whilst $100 \%$ of trainees were able to attend when the teaching went online. This shows that trainees attendance rates were higher when teaching was provided online compared to face-to-face sessions. The reasons could be due to logistical issues, trainees being able to learn at the comfort of their home during their annual leave or after an on-call shift. Comments by some trainees also supported this idea:

"Much easier, saves transport issues and travelling, all content can be shared digitally"

"Saves on long distance travelling. Far more convenient to attend teaching, even when on call as you can attend briefly on a mobile or iPad and therefore maintain a decent attendance record"

J Endolum Endourol Vol 3(4):e25-e31; November 16, 2020

This article is distributed under the terms of the Creative Commons Attribution-Non Commercial 4.0 International License. (c) Wong 
Would the Quality of Teaching Be Affected with Online Learning?

Our study showed that the quality of teaching was not any different between face-to-face and online teaching. When an independent t-test was carried out, the mean score for face-to-face and online teaching were 7.95 and 8.11 respectively. However, the p value was 0.316 , indicating that the data was not statistically significant. Some trainees also did not feel that the quality of teaching was affected by the change in circumstances, as evident by one comment:

"Much prefer face to face for the social aspect, meeting new bosses etc. But in my opinion virtual and face to face roughly equally effective"

FIG. 1 Example of survey questionnaire.

\section{Questionnaire}

1. Before the COVID-19 pandemic, were you able to attend at least $80 \%$ of your face-to-face regional teaching sessions?

Yes

No

2. Since the introduction of virtual teaching during the COVID-19 pandemic, were you able to attend at least $80 \%$ of your regional teaching sessions?

Yes

No

3. On a scale of 1 to 10 , with 1 being terrible and 10 being excellent, how would you rate the quality of your face-to-face teaching sessions?
1
23
45
6
89
10

4. On a scale of 1 to 10 , with 1 being terrible and 10 being excellent, how would you rate the quality of your online/virtual teaching sessions?
1
2
3
4
5
$6 \quad 7$
89
10

5. Do you think it will be more beneficial for you if all future teaching sessions are taught online?

Yes

No

6. Any further comments?

J Endolum Endourol Vol 3(4):e25-e31; November 16, 2020

This article is distributed under the terms of the Creative Commons Attribution-Non

Commercial 4.0 International License. (c) Wong 
FIG. 2 Comparing attendances of $\geq 80 \%$ for pre-COVID face-to-face teaching and online teaching.

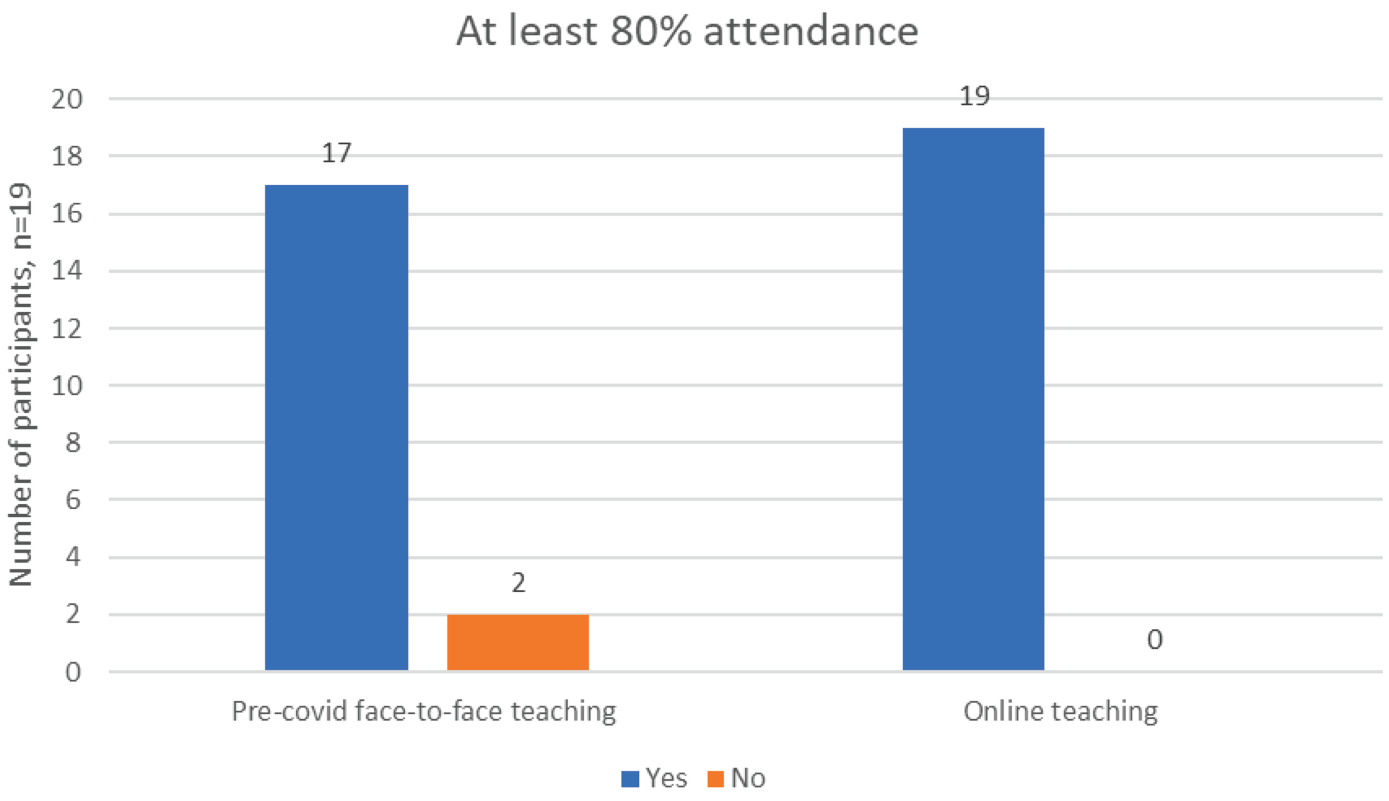

FIG. 3 Quality of face-to-face teaching sessions.

On a scale of 1-10, 1 being terrible and 10 being excellent, how would you rate the quality of the face-to-face teaching sessions?

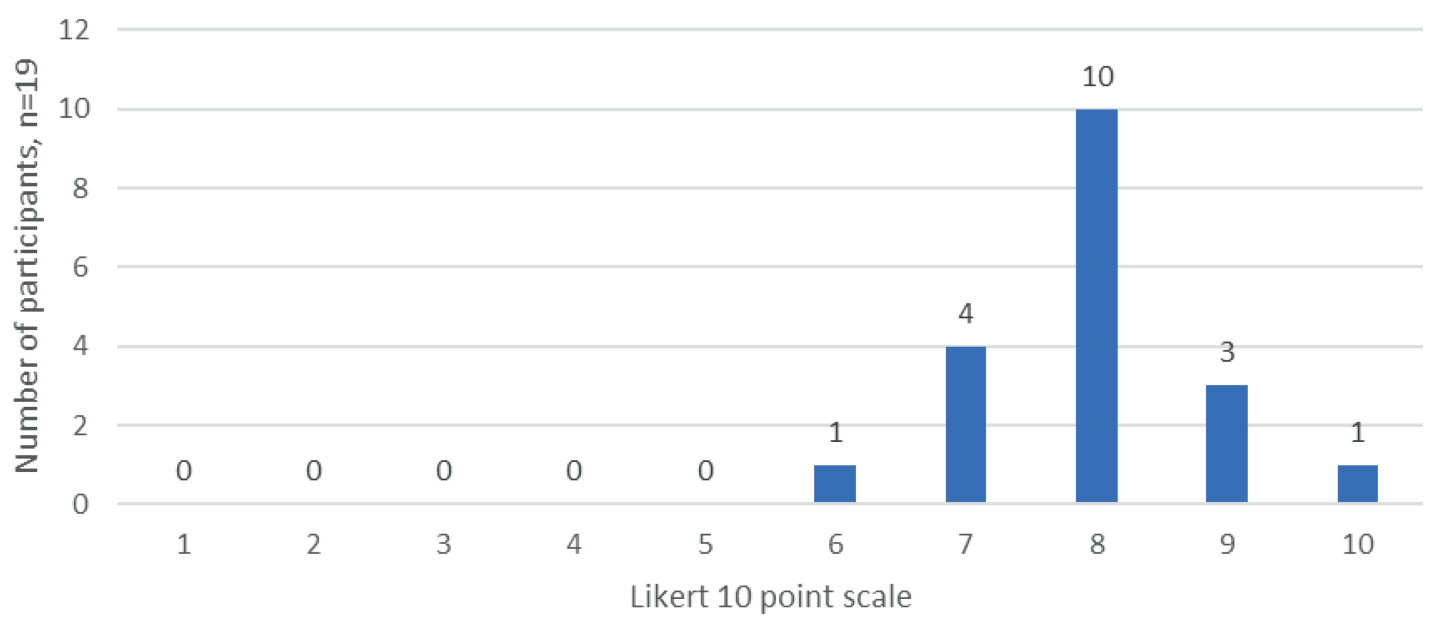

Srivastava et al conducted a similar cross-sectional study to assess the utility of online teaching among postgraduate surgical doctors in India. ${ }^{4}$ The study looked at the accessibility to teaching, communication ease during classes, quality of teaching and overall opinion for online teaching. The accessibility ease and overall opinion showed a sufficient score whilst the communication ease and quality of online teaching were favourable. 
FIG. 4 Quality of online teaching.

On a scale of 1-10, 1 being terrible and 10 being excellent, how would you rate the quality of the online teaching sessions?

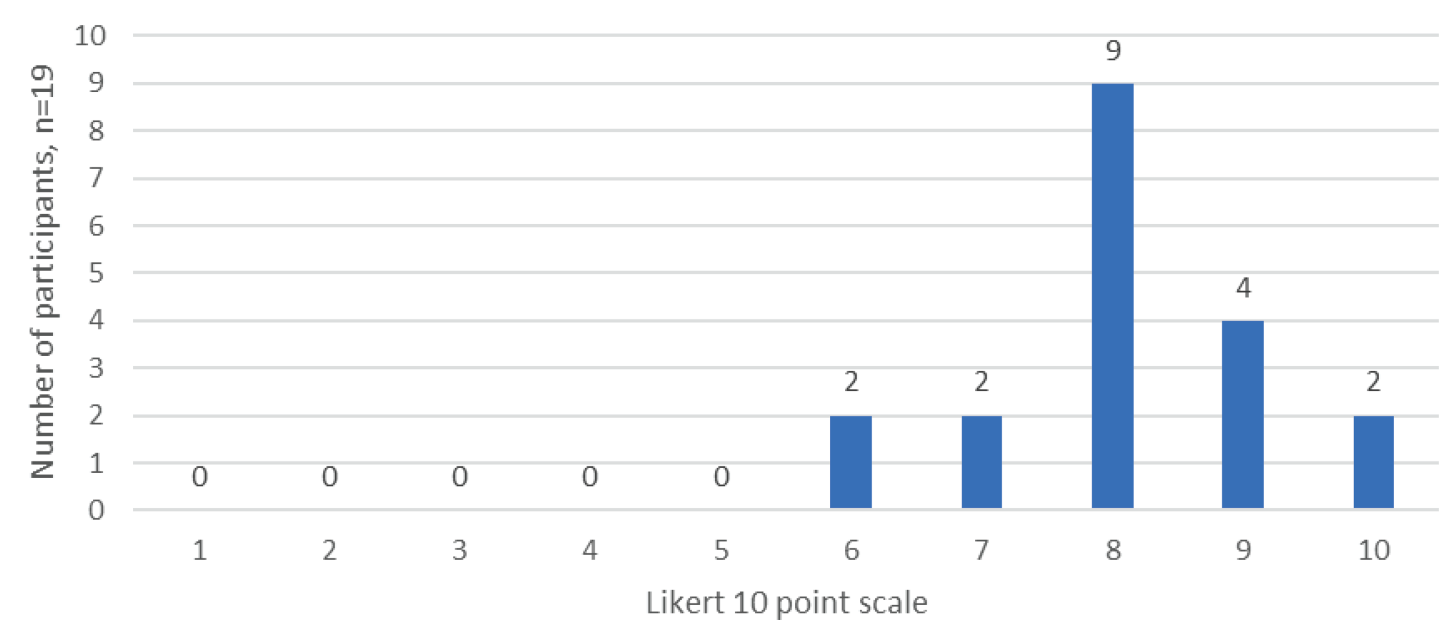

FIG. 5. Graph comparing the mean for both methods with their corresponding error bars. Confidence levels were 95\%.

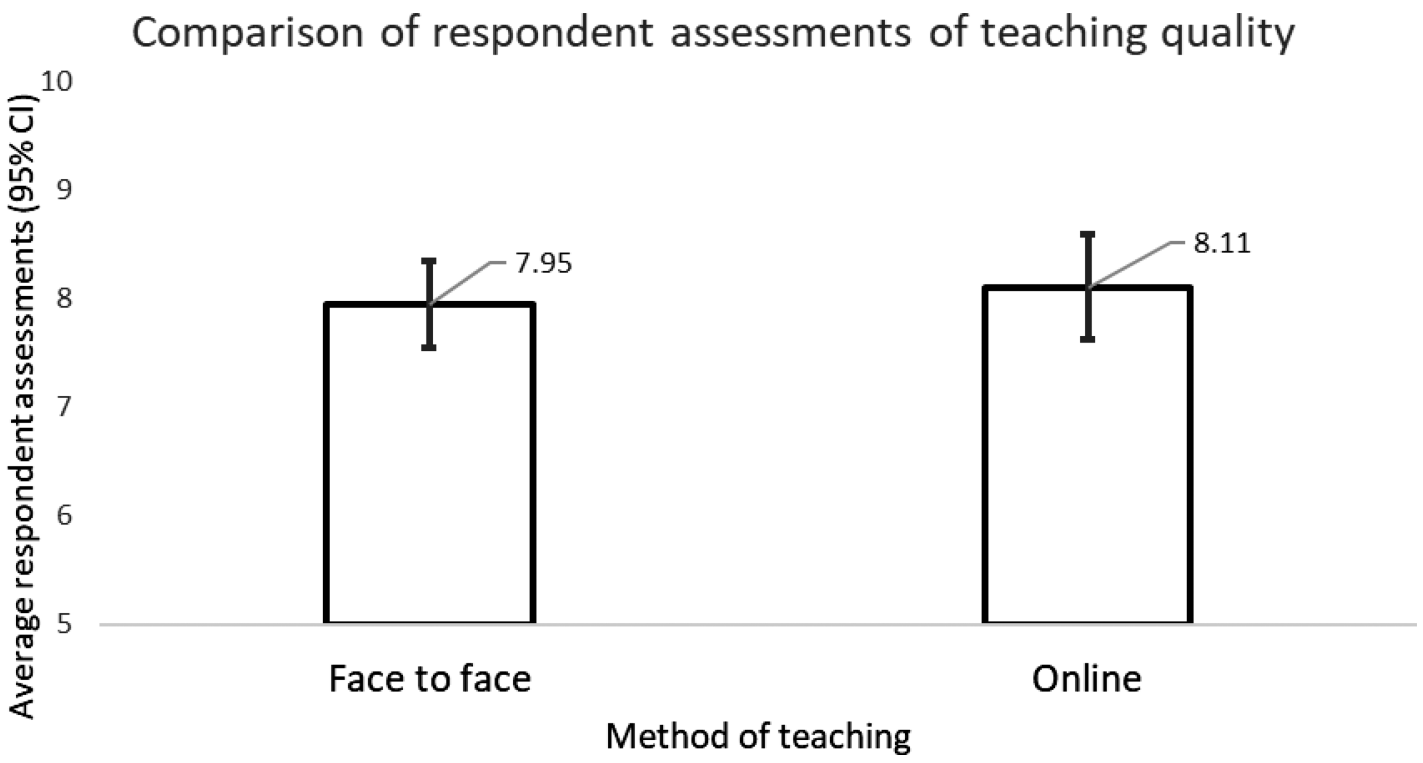

Agarwal and Kaushik also conducted a study among paediatric trainees in India. ${ }^{8}$ The study looked at the student's perception of online learning during the pandemic. $97 \%$ of the participants found the sessions to be relevant to their learning needs and $95 \%$ found online learning to be interesting and enjoyable.
Moving Forward: Face-To-Face, Online Teaching or a Hybrid?

Although the quality of teaching was not statistically different for both groups, 58\% $(n=11)$ of trainees still preferred face-to-face over online teaching. Feedback from trainees identified the 
FIG. 6 Trainees views on future teaching sessions.

\section{Should all future sessions be taught online?}

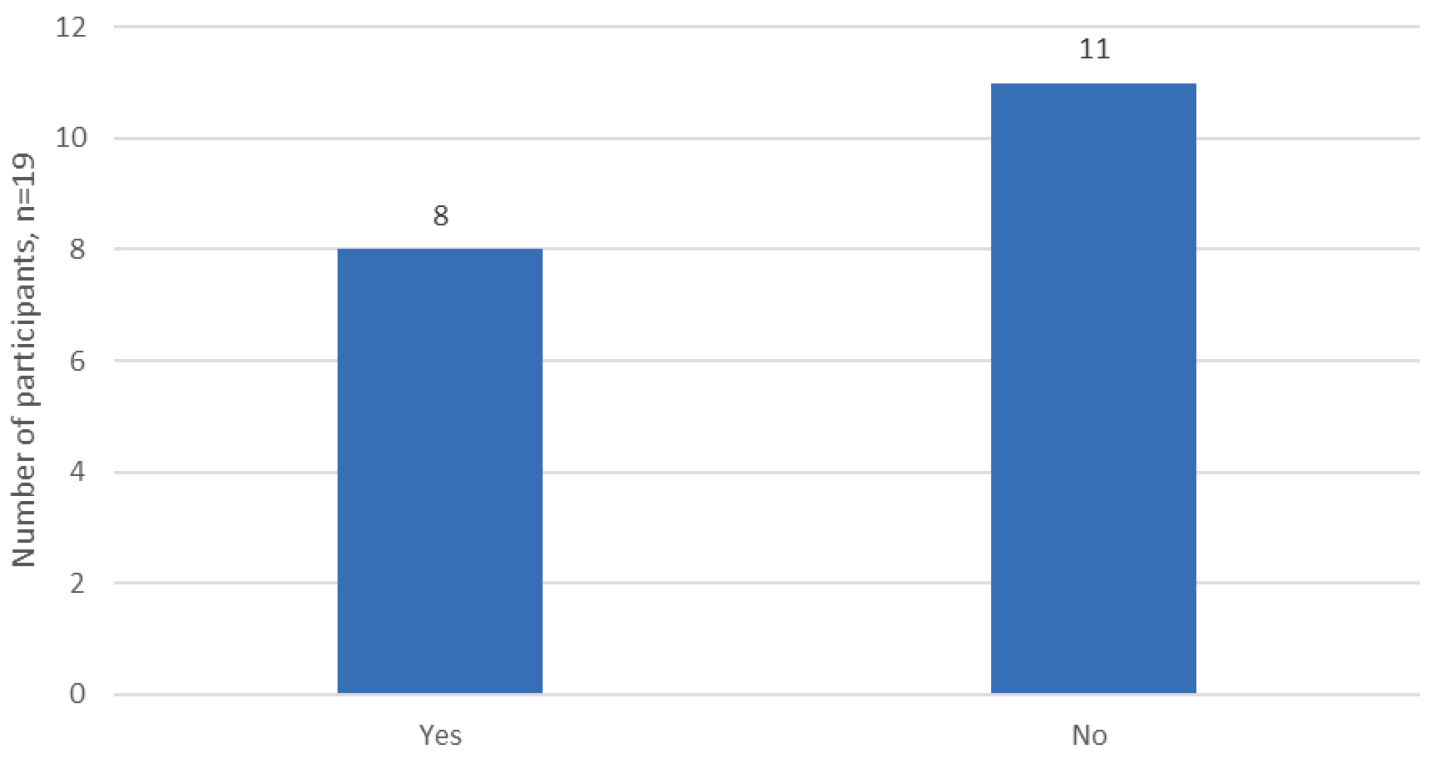

major drawback with online teaching sessions. The majority that preferred face-to-face teaching missed the social aspect and level of interaction they had with the lecturer and fellow trainees, as highlighted by several comments:

"Face to face meetings are always a plus to meet your colleagues"

"Although it is convenient not to travel, I really miss attending teaching and catching up with my colleagues and friends. I think the opportunity for networking and asking more questions to expert speakers, is lost with the virtual teaching. I think it is important that as trainees together in the region we have opportunities to meet up and share experiences and learn from each other and I don't think you can replicate this online. Some people may prefer chatting in small groups during break times than saying something in front of the whole group. I don't think we can have face to face teaching now due to COVID but would like to see it reinstated to some degree afterwards"

"Though teaching has been very good, the downsides are that we cannot catch up with fellow trainees as we used to"

"We miss socialising with fellow trainees"

"There is less interaction, questions and debate on online teaching days, which is a shame. I feel it should be done due to necessity rather than default. Although not having to travel long distances is nice!"

Nevertheless, $42 \%(n=8)$ of trainees recommended that all future sessions should be taught online. Verma et al also found that $47 \%$ of medical students wanted online classes to be part of their curriculum after COVID-19. Agarwal and Kaushik concluded that online learning is cheap, feasible and should be made part of the postgraduate curriculum. ${ }^{8}$

Most trainees seem to favour the hybrid method for future teaching sessions. Many recommended a mixture of face-to-face and online teaching sessions. Some of the comments included:

"I will prefer a mixture. Virtual teaching on some days and face to face on others"

"I believe a mix of face-to-face and online teaching is best suited as you can balance educational needs with networking"

"I have liked the virtual days because they take away the stress of traveling to the host centres, meaning you're in a relaxed mood and able to concentrate better, but it has had a negative impact on the social interaction within the group of trainees, plus the smaller centres miss out on raising their profile. In the future, once restrictions are lifted there should be a combination of virtual and face-to-face days" 
"A mixture of online and face to face would be best. Online works well for information delivery but lacks opportunity to meet teams and trainers and also lacks interactivity"

This hybrid or blended learning approach has also gained popularity across the globe. Vodovar et al conducted a survey assessing their newly implemented blended approach in teaching emergency medicine and intensive care at Paris-Diderot University. ${ }^{10}$ Their study found that $98 \%$ of students were satisfied with blended learning and the use of blended learning reached more students compared to traditional methods. Liu et al also performed a meta-analysis looking at the effectiveness of the blended approach. ${ }^{11}$ The study found a consistent positive effect with the blended learning approach compared to the non-blended approach.

\section{CONCLUSION}

The impact of COVID-19 has almost forced all undergraduate and postgraduate education to have a form of virtual presence. Our study found that the quality of online teaching sessions are equal to that of face-to-face teaching sessions, with the added benefit of accessibility and increase in attendance among trainees. However, the main drawback that was identified with online teaching is the lack of interactivity and social networking among trainees. At present, all teaching sessions will have to remain online. However, online teaching sessions should not be abandoned in the future. Majority of trainees found the hybrid approach of mixing face-to-face and online teaching sessions to be the best method moving forward.

\section{REFERENCES}

1. Health Education England. West Midlands Postgraduate School of Surgery - Urology Urology training programme in the West Midlands [Internet].
Available at: https://www.westmidlandsdeanery.nhs. uk/postgraduate-schools/-surgery/urology/training -programme

2. Sneyd JR, Mathoulin SE, O'Sullivan EP, et al. Impact of the COVID-19 pandemic on anaesthesia trainees and their training. Br J Anaesth 2020 Oct;125(4):450-5.

3. Upadhyaya GK, Jain VK, Iyengar KP, et al. Impact of COVID-19 on post-graduate orthopaedic training in Delhi-NCR. J Clin Orthop Trauma 2020 Oct;11:S687-95.

4. Srivastava V, Pandey V, Tiwari P, et al. Utility of realtime online teaching during COVID era among surgery postgraduates. Indian J Surg 2020 Oct;82(5):762-8.

5. Verma A, Verma S, Garg P, Godara R. Online teaching during COVID-19: Perception of medical undergraduate students. Indian J Surg 2020 Jun;82(3):299-300.

6. Longhurst GJ, Stone DM, Dulohery K, et al. Strength, Weakness, Opportunity, Threat (SWOT) analysis of the adaptations to anatomical education in the United Kingdom and Republic of Ireland in response to the COVID-19 Pandemic. Anat Sci Educ 2020 May;13(3):301-11.

7. Kapasia N, Paul P, Roy A, et al. Impact of lockdown on learning status of undergraduate and postgraduate students during COVID-19 pandemic in West Bengal, India. Child Youth Serv Rev 2020 Sep;116:105194.

8. Agarwal S, Kaushik JS. Student's Perception of Online Learning during COVID Pandemic. Indian J Pediatr 2020 Jul;87(7):554-554.

9. Huynh R. The role of e-learning in medical education: Acad Med 2017 Apr;92(4):430.

10. Vodovar D, Ricard JD, Zafrani L, et al. Évaluation d'un enseignement multimodal intégrant du e-learning dans l'apprentissage de la réanimation et de la médecine d'urgence au cours du second cycle des études médicales. Rev Médecine Interne 2020 Jun;41(6):368-74.

11. Liu Q, Peng W, Zhang F, et al. The effectiveness of blended learning in health professions: Systematic Review and Meta-Analysis. J Med Internet Res 2016 Jan 4;18(1):e2. 